\title{
NEUTRON SPECTRA FROM CALIFORNIUM-252 WIRE SOURCES
}

\author{
T. R. HEROLD
}

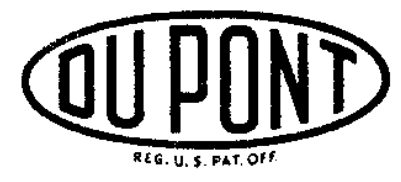

Savannah River Laboratory

Aiken, South Carolina 


\section{NOTICE}

This report was prepared as an account of work sponsored by the United States Government. Neither the United States nor the United States Atomic Energy Commission, nor any of their employees, nor any of their contractors, subcontractors, or their employees, makes any warranty, express or implied, or assumes any legal liability or responsibility for the accuracy, completeness or usefulness of any information, apparatus, product or process disclosed, or represents that its use would not infringe privately owned rights.

Printed in the United States of America Available from

National Technical Information Service

U. S. Department of Commerce 5285 Port Royal Road

Springfield, Virginia 22151

Price: Printed Copy $\$ 3.00$; Microfiche $\$ 0.95$ 


\title{
NEUTRON SPECTRA FROM \\ CALIFORNIUM-252 WIRE SOURCES
}

\author{
by \\ T. R. Herold \\ Approved by \\ D. E. Waters, Manager \\ Laboratory Operations and Services
}

March 1973

E. I. DU PONT DE NEMOURS \& COMPANY SAVANNAH RIVER LABORATORY

AIKEN, S. C. 29801

CONTRACT AT(07-2)-1 WITH THE

UNITED STATES ATOMIC ENERGY COMMISSION 


\begin{abstract}
Neutron spectra from four types of ${ }^{252} \mathrm{Cf}$ wire sources were measured with commercially available ${ }^{3} \mathrm{He}$ and ${ }^{6} \mathrm{Li}$ "sandwich" spectrometers. The sources all emitted essentially pure fission neutron spectra. The presence of non-radioactive cationic impurities at concentrations up to the accepted limit of four times the californium content produced insignificant amounts of additional neutrons. Spectra from the four source types were obtained between 0.5 and $4.7 \mathrm{MeV}$ with the ${ }^{3} \mathrm{He}$ spectrometer and between 0.2 and $5.0 \mathrm{MeV}$ with the ${ }^{6} \mathrm{Li}$ spectrometer with no detectable variation from the fission spectrum obtained from an electroplated source containing high-purity ${ }^{252} \mathrm{Cf}$. The neutron spectrum from a wire source containing samarium and terbium did not differ significantly from the ${ }^{252} \mathrm{Cf}$ fission spectrum between 0.5 and $8.6 \mathrm{MeV}$ as measured with the ${ }^{3} \mathrm{He}$ spectrometer.

The instrumentation and techniques for fissile neutron detection and counting are described. Spectrometer response to neutrons of different energies was verified by resolving the energy groups from a plutonium-beryllium neutron source.
\end{abstract}




\section{CONTENTS}

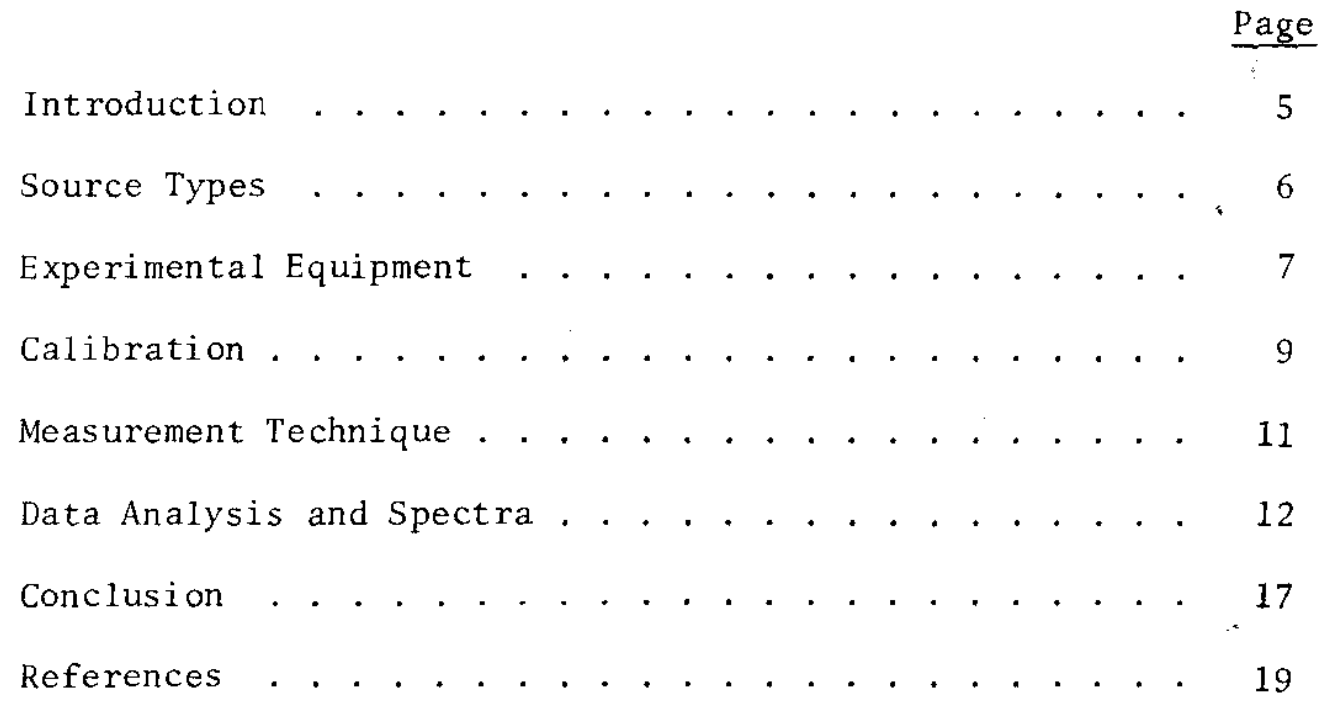




\section{INTRODUCTION}

The USAEC is providing sources of ${ }^{252} \mathrm{Cf}$ for various industrial, medical, and nuclear applications. In support of this program. the Savannah River Laboratory (SRL) has developed a ${ }^{252} \mathrm{Cf}$-bearing palladium metal wire that contains a uniform concentration of ${ }^{252} \mathrm{Cf}$ per unit length and minimizes wet chemistry techniques in source preparation. ${ }^{2}$ The wire production process includes chemically plating ${ }^{252} \mathrm{Cf}$ oxalate with palladium, calcining the resulting powder to cermet powder, compressing and sintering the cermet powder into a high density pellet, and rolling the pellet into wire.

During early development work on the cermet, various carriers that would ensure complete precipitation of sma11 amounts of ${ }^{252} \mathrm{Cf}$ oxalate were investigated. Samarium, cerium, and terbium were tried as carriers because their chemical properties were similar to californium. Terbium was selected for production use mainly because of its low cross section for thermal neutron capture.

The elemental composition of a typical production wire source for commercial use is palladium with relatively small amounts of ${ }^{252} \mathrm{Cf}$, terbium, and oxygen. Smal1 quantities of calcium, sodium, potassium, barium, magnesium, aluminum, copper, iron, zinc, and lead are present mainly from impurities in the ${ }^{252} \mathrm{Cf}$ feed solution. Alpha particles from ${ }^{252} \mathrm{Cf}$ induce $(\alpha, n)$ reactions in some of these impurity elements. The $(\alpha, n)$ yields for sodium, magnesium, and aluminum were reported in $1944 .^{3}$ The $(\alpha, n)$ yield from oxygen is well known, ${ }^{4,5}$ and derives mainly from the ${ }^{18} 0$ isotope in natural oxygen. Calculations showed that ${ }^{18} \mathrm{O}(\alpha, n){ }^{21} \mathrm{Ne}$ reactions would produce more neutrons than all other impurities combined. However, these neutrons were calculated to contribute less than $1 \%$ of the tota 1 neutrons from the wire source. Some of the reaction yields and Q-values are not well known so that calculations could give an erroneous idea of the total neutron yield from the impurities. Because of the uncertainty in the total neutron yield, neutron spectral measurements were undertaken to determine that the wire sources emitted an essentially pure fission neutron spectrum. 


\section{SOURCE TYPES}

Four sources were prepared by different techniques. They contained varying impurities as listed in Table 1. Neutron spectra were obtained on all four sources.

Feed specifications for the ${ }^{252} \mathrm{Cf}$ require that total actinide and 1 anthanide impurities sha11 not exceed the californium content, and nonradioactive cations shall not exceed four times the californium content. ${ }^{6}$ Major nonradioactive impurities are oxygen, sodium, calcium, potassium, barium, magnesium, aluminum, copper, iron, zinc, and lead, as determined by spark source mass spectrographic analysis of ${ }^{252} \mathrm{Cf}$ feed. Isotopic purity of the californium is typically $79 \%{ }^{252} \mathrm{Cf}, 15 \%{ }^{250} \mathrm{Cf}, 4 \%{ }^{251} \mathrm{Cf}$, and $2 \%{ }^{249} \mathrm{Cf}$.

TABLE 1. WIRE SOURCES

\begin{tabular}{|c|c|c|c|c|c|c|c|}
\hline Source & $\begin{array}{c}\text { Fabrication } \\
\text { Process } \\
\end{array}$ & $\begin{array}{l}\text { Palladium } \\
\text { Content, } \mathrm{g}\end{array}$ & Carrier & $\frac{r \text { Conte }}{\mathrm{Tb}}$ & $\frac{\mathrm{nt}, \mathrm{g}}{\mathrm{Ce}}$ & $\begin{array}{c}{ }^{252} \mathrm{Cf} \\
\text { Content, } \\
\mu g \\
\end{array}$ & Size, cm \\
\hline Al loy 1 & $\begin{array}{l}\text { Chem. Plating } \\
\text { plus Melting } b\end{array}$ & 1.45 & 0.0003 & 0.003 & - & 175 & $0.1 \times 0.1 \times 10.7$ \\
\hline $1005-C$ & Admix & 1.0 & - & - & 0.0126 & 805 & $0.08 \times 0.08 \times 11$ \\
\hline $1014-\mathrm{C}$ & Chem. Plating & 1.0 & 0.003 & - & - & 607 & $0.08 \times 0.08 \times 14.6$ \\
\hline $1021-\mathrm{C}$ & Chem. Plating & 1.0 & - & 0.003 & - & 25.8 & $0.1 \times 0.1 \times 8.6$ \\
\hline
\end{tabular}

a. Small samples of the first three types that contained between 5 and $20 \mu{ }^{252} \mathrm{Cf}$ were used in the spectrometer measurements.

b. Portions of several cermet wires were melted at $1600^{\circ} \mathrm{C}$ in a reducing atmosphere to demonstrate that an alloy could be made. 


\section{EXPERIMENTAL EQUIPMENT}

The neutron spectra were measured with commercially available ${ }^{6} \mathrm{Li}$ and ${ }^{3} \mathrm{He}$ spectrometers and associated instrumentation as shown in Figure 1. Each spectrometer contained two matched surface-barrier detectors in a face-to-face or sandwich geometry plus a quantity of neutron-sensitive material, either ${ }^{6} \mathrm{LiF}$ or ${ }^{3} \mathrm{He}$. The technical specifications and operating characteristics for the ${ }^{3} \mathrm{He}$ and ${ }^{6} \mathrm{Li}$ spectrometer were given in a previous report.?

The charged particle pairs that are produced by neutrons incident on the sensitive material are detected simultaneously in the two detectors. The resulting pulses are amplified in two separate channels. Each channel has double shaping modes with $0.2-\mu s e c$ time constants in the multimode amplifiers. The two output pulses from the multimode amplifiers are summed to produce a pulse with amplitude proportional to the energy of the incident neutron plus the reaction $Q$-value $\left(4.78 \mathrm{MeV}\right.$ for ${ }^{6} \mathrm{Li}$ and $0.76 \mathrm{MeV}$ for ${ }^{3} \mathrm{He}$ events).* A biased amplifier expands the portion of interest in the total energy spectrum, and a pulse stret'cher ensures compatibility with the input requirements of the multichannel analyzer.

The output pulses from the multimode amplifiers are also fed to crossover pickoff circuits that provide timing pulses to the fast coincidence unit. When the two timing pulses occur within the coincidence resolving time (adjusted to 110 nanoseconds for this work), a coincidence output signal is generated, inverted, and used to gate the multichannel analyzer and record the event. The fast coincidence unit eliminates signals-from unwanted nuclear events (such as ${ }^{3} \mathrm{He}$ recoils) but does not eliminate coincidence background events (such as gamma rays or

$$
\text { * The nuclear reactions are: } \begin{aligned}
&{ }^{6} \mathrm{Li}+{ }^{1} \mathrm{n} \rightarrow{ }^{3} \mathrm{H}+{ }^{4} \mathrm{He}+4.78 \mathrm{MeV} \\
&{ }^{3} \mathrm{He}+{ }^{1} \mathrm{n} \rightarrow{ }^{1} \mathrm{H}+{ }^{3} \mathrm{H}+0.76 \mathrm{MeV}
\end{aligned}
$$

The sum pulse from the ${ }^{6} \mathrm{Li}$ spectrometer is the alpha pulse from one surface barrier detector added to the corresponding triton pulse from the opposite detector, or vice versa. For the ${ }^{3} \mathrm{He}$ spectrometer, the sum pulse is the proton pulse from one detector added to the corresponding triton pulse from the opposite detector. 
energetic protons passing through both detectors). Coincidence background events are removed by making two source measurements: one measurement with the neutron-sensitive spectrometer and a second measurement under identical conditions with a background spectrometer. The background obtained by the second measurement is subtracted, channel-by-channel, from the counts obtained by the first measurement.

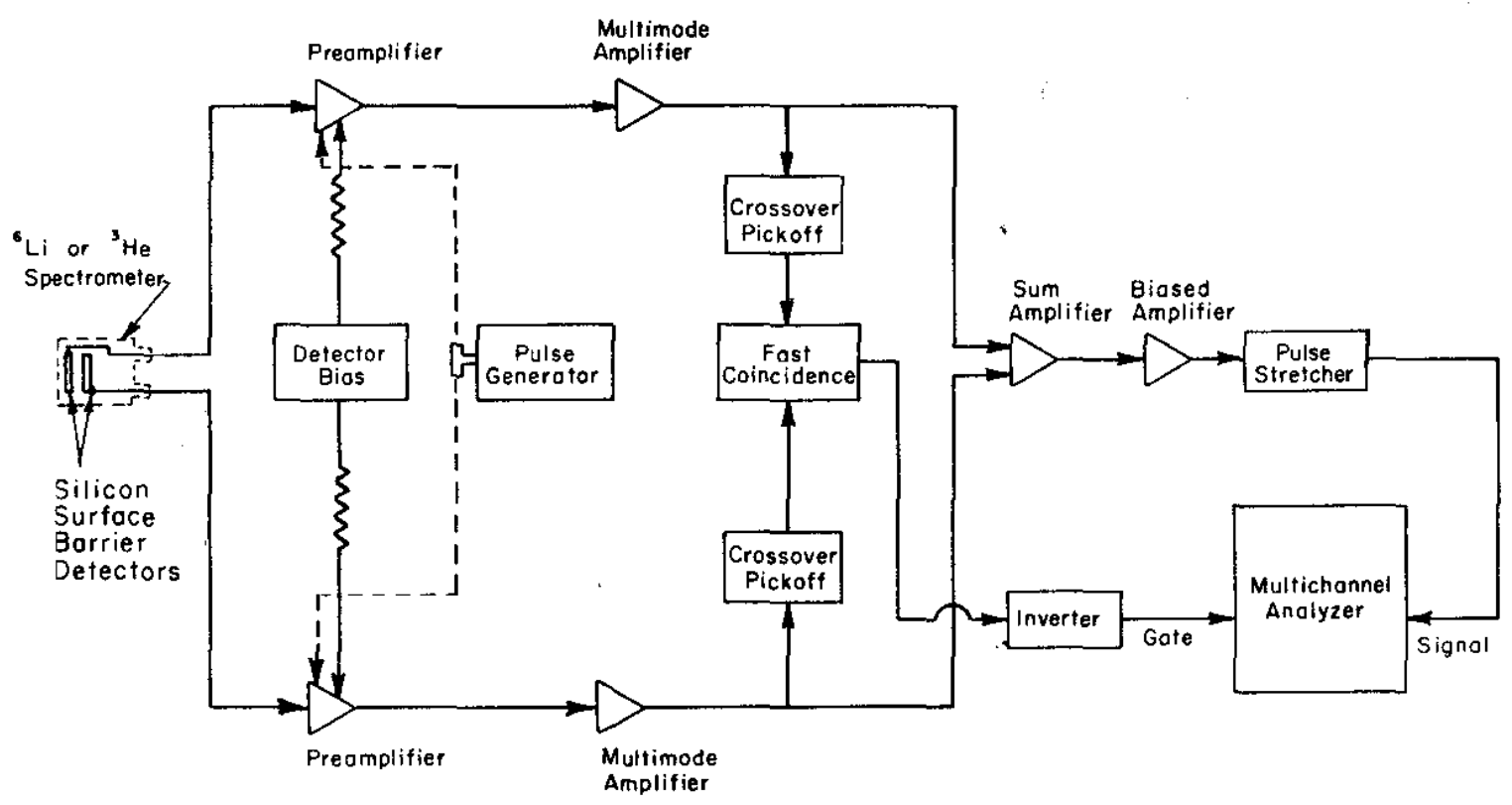

FIG. 1 SPECTROMETER INSTRUMENTATION 


\section{CALIBRATION}

The spectrometers were calibrated with the peak arising from ${ }^{6} \mathrm{Li}$ plus thermal neutrons $(4.78 \mathrm{MeV})$ and with the peak arising from ${ }^{3} \mathrm{He}$ plus thermal neutrons $(0.76 \mathrm{MeV})$ by determining the linearity of response of the electronic system with an ORTEC* Precisior. Pulse Generator, and then moving the ${ }^{6} \mathrm{Li}$ or ${ }^{3} \mathrm{He}$ thermal peak over the analyzer scale in discrete steps by changing the electronic gain. The system was then adjusted to analyze and record neutron energies over the desired energy interval.

Actual thermal peak data (as displayed on the readout oscilloscope of the multichannel analyzer) is shown in Figure 2. This figure also shows the calibration technique. The peak on the left is that from ${ }^{6} \mathrm{Li}$ thermal neutrons. The low energy fal1off from this peak was biased out in the electronic system. On the right is the ${ }^{6} \mathrm{Li}$ thermal peak obtained by doubling the electronic gain. The energy difference between these two peaks is then $4.78 \mathrm{MeV}$, and the energy calibration as $\mathrm{keV} / \mathrm{channel}$ is simply obtained by dividing $4.78 \mathrm{MeV}$ by the total number of analyzer channels between the two peaks. The ${ }^{3} \mathrm{He}$ spectrometer was similarly calibrated. This calibration technique has been used in neutron spectroscopic work at SRL since $1965^{8}$ and automatically compensates for charged particle energy loss in the ${ }^{6} \mathrm{LiF}$ coating or in the ${ }^{3} \mathrm{He}$ gas. The energy loss in the coating or gas is assumed to be the same for neutrons of all energies.

An additional calibration check is made by momentarily switching out the circuit coincidence requirement and observing the individual alpha peak at $2.05 \mathrm{Mev}$ and the triton peak at $2.73 \mathrm{MeV}$ as well as the sum peak at $4.78 \mathrm{MeV}$ from thermal neutron reactions in ${ }^{6} \mathrm{Li}$. One similarly observes the individual triton peak at $0.190 \mathrm{MeV}$ and the proton peak at $0.570 \mathrm{MeV}$ as well as the sum peak at $0.76 \mathrm{MeV}$ from thermal neutron reactions in ${ }^{3} \mathrm{He}$. These techniques have also been used at SRL since 1965. The ${ }^{6} \mathrm{Li}$ technique was recently used by Yang in his investigation of a ${ }^{6} \mathrm{Li}$ sandwich spectrometer. ${ }^{9}$

* ORTEC Incorporated, Oak Ridge, Tenn. 


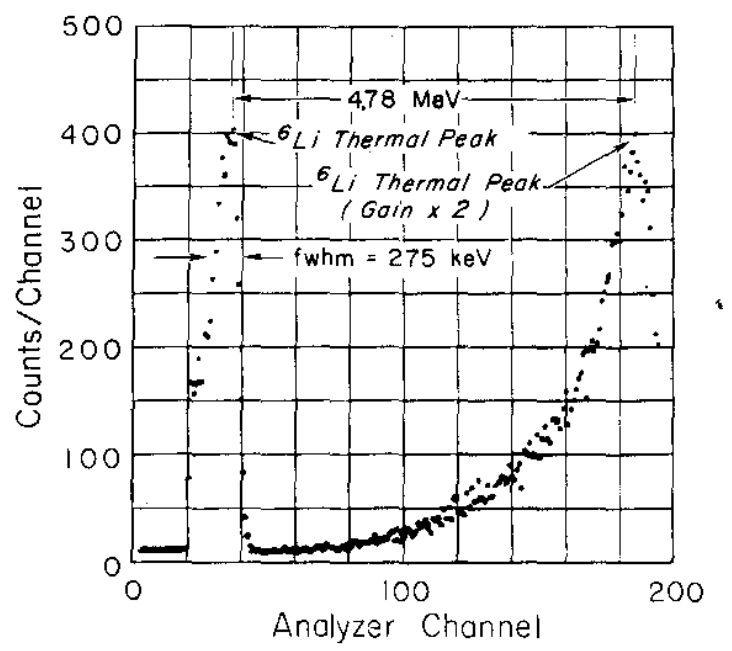

FIG. 2 CALIBRATION WITH ${ }^{6}$ Li THERMAL- PEAK 


\section{MEASUREMENT TECHNIQUE}

During source measurements, the spectrometers were covered with $0.076 \mathrm{~cm}$ of cadmium to shield them from thermal neutrons, and enclosed in a $1.3-\mathrm{cm}$-thick lead housing to shield them from gamma radiation. This assembly was placed inside a thin-walled aluminum housing in which the temperature was controlled at $30^{\circ} \pm 0.5^{\circ} \mathrm{C}$. The source to be measured was positioned at the appropriate distance from the spectrometer housing to prevent radiation damage to the detectors and overloading of the electronic system. The spectrometer housing and source were centrally located inside a shielded facility at least 1.5 meters away from any 1 arge object that could scatter neutrons.

Typical measurement times were 48 to 72 hours for the ${ }^{6} \mathrm{Li}$ spectrometer (with an efficiency of $\approx 10^{-6}$ in the $\mathrm{MeV}$ range) and 12 to 24 hours for the ${ }^{3} \mathrm{He}$ spectrometer (with an efficiency of $\approx 10^{-5}$ over the same range).

The neutron data in each case were accumulated in 200 channels of a 400-channel analyzer. The remaining 200 channels were used periodically to check the instrumentation for drift with the pulse generator and, if necessary, to make small gain adjustments. 


\section{DATA ANALYSIS AND SPECTRA}

Actual data obtained with the ${ }^{3} \mathrm{He}$ spectrometer and Alloy 1 source were displayed on the readout oscilloscope of the multichannel analyzer (Figure 3). The signal plus background data were accumulated with the spectrometer filled with ${ }^{3} \mathrm{He}$ to $1200-$ $\mathrm{cm}-\mathrm{Hg}$, and the background data were accumulated with the spectrometer evacuated to $5 \mathrm{\mu m}$. The background data were subtracted from the signal plus background data to obtain the uncorrected signal. The energy range for these data was 0.52 to $4.77 \mathrm{MeV}$ over 200 analyzer channels with a calibration of $21.8 \mathrm{keV} / \mathrm{channe}$.

The energy interval for data analysis was selected within the energy resolution of the spectrometer for reliably determining the shape of the spectrum and wide enough to contain enough counts for an acceptable statistical spread in the resulting data. The energy interval in this case was 5 analyzer channels or $109 \mathrm{keV}$, and the energy resolution of the spectrometer was about $200 \mathrm{keV}$ with the $1200-\mathrm{cm}-\mathrm{Hg}{ }^{3} \mathrm{He}$ filling. The total of background-corrected counts in each energy interval was corrected with the ${ }^{3} \mathrm{He}(n, \rho)$ cross section value at the midpoint of the interval. The resulting data for the corrected spectrum were generally plotted as a histogram of normalized counts per energy interval versus neutron energy.

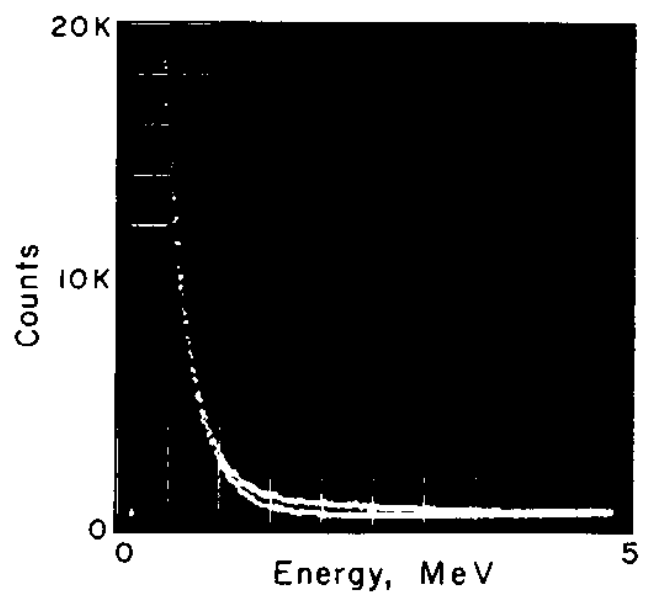

20K Full Scale to Show Complete Spectra. Bottom Curve Is Background

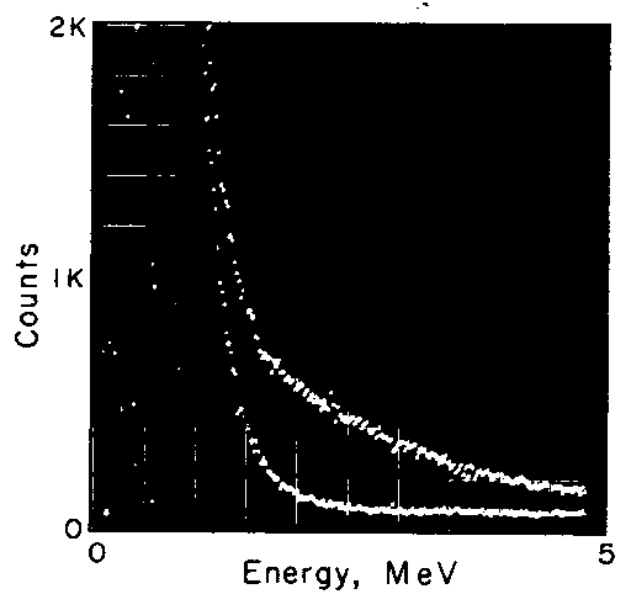

Same Spectra at $2 \mathrm{~K}$ Full Scale to Enhance High Energy Region

FIG. $3{ }^{3}$ He SPECTROMETER DATA FROM ALLOY 1 SOURCE 
The Alloy 1 source was studied in more detail than the other sources because it contained both terbium and samarium. Additional spectra were accumulated with the ${ }^{3} \mathrm{He}$ spectrometer adjusted to cover an energy range from 1.25 to $8.67 \mathrm{MeV}$ over 200 analyzer channels with a calibration of $39.1 \mathrm{keV} / \mathrm{channel}$. A plot of corrected data was obtained over the two energy ranges (Figure 4). The neutron spectrum from the wire source containing samarium and terbium did not differ significantly from the ${ }^{252} \mathrm{Cf}$ fission spectrum ${ }^{10}$ between 0.5 and $8.6 \mathrm{MeV}$. From the data obtained and assuming that $(\alpha, n)$ neutrons would mainly occur in the 1 to $3 \mathrm{MeV}$ energy range, a variation of about $1.5 \%$ from the fission neutron spectrum was detectable with the ${ }^{3} \mathrm{He}$ spectrometer. The ${ }^{3} \mathrm{He}$ spectrometer was used for this definitive measurement because of its relatively high efficiency. The maximum drift observed during the measurements amounted to two channels, or about $40 \mathrm{keV}$ for the lower energy range and $80 \mathrm{keV}$ for the higher energy range.

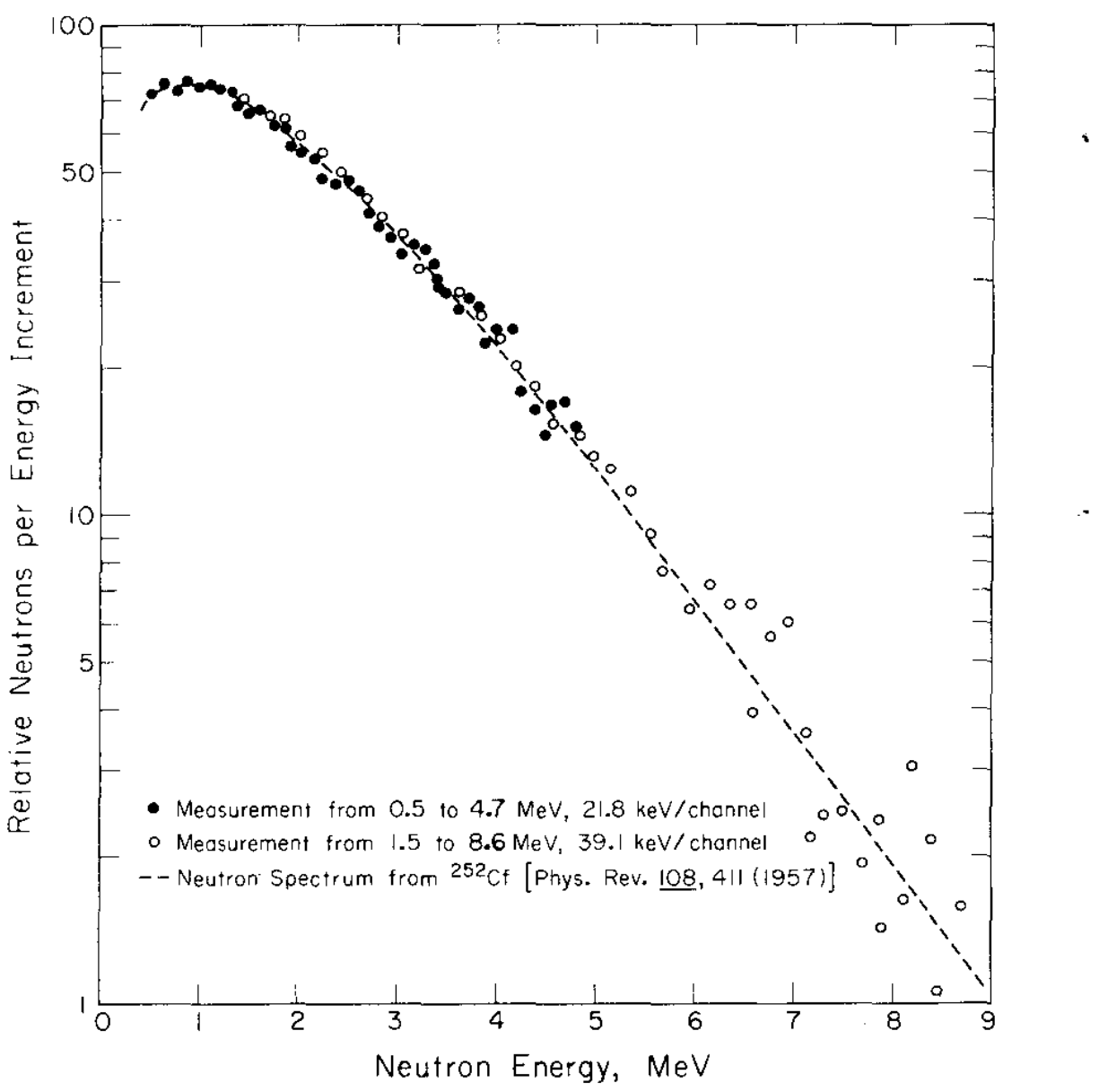

FIG. 4 NEUTRON SPECTRUM OF ALLOY 1 SOURCE WITH ${ }^{3} \mathrm{He}$ SPECTROMETER 
Data were obtained during a 96 hour run with the ${ }^{6} \mathrm{Li}$ spectrometer and Alloy 1 source, and displayed on the readout oscilloscope of the multichannel analyzer (Figure 5). The energy range for these data was 0.20 to $5.08 \mathrm{MeV}$ over 200 analyzer channels with a calibration of $27.9 \mathrm{keV} / \mathrm{channel}$. The energy interval for data analyses was five analyzer channels or $140 \mathrm{keV}$, and the energy resolution of the spectrometer was about $300 \mathrm{keV}$. Note that relatively few background counts were obtained over this energy interval. The low energy peak in Figure 5 is due primarily to the resonance in the ${ }^{6} \mathrm{Li}(\mathrm{n}, \mathrm{t})$ cross section that occurs around $250 \mathrm{keV} .{ }^{11}$ The total of background-corrected counts in each energy interval was corrected with the ${ }^{6} \mathrm{Li}(n, t)$ cross section value at the midpoint of the interval to obtain the histogram shown in Figure 6 . The maximum drift observed in this case was three channels, or about $80 \mathrm{keV}$.

Both spectrometers were used in measuring the other wire sources listed in Table 1 . The spectra obtained were essentially the same as from Alloy 1. An electroplated source containing high-purity ${ }^{252} \mathrm{Cf}$ was also measured with the ${ }^{3} \mathrm{He}$ spectrometer and exhibited the same spectrum as the four wire sources.

Data were collected during a 71 hour run with the ${ }^{3} \mathrm{He}$ spectrometer on a 1-curie Pu-Be source (Figure 7). The spectrometer was adjusted to cover the energy range from 1.25 to $8.67 \mathrm{MeV}$ over 200 channels as previously described. The intensity maxima at $3.2,4.7$, and $7.7 \mathrm{MeV}$ as well as the characteristic dip at $6.1 \mathrm{MeV}$ are apparent in the uncorrected data. The corrected data points were normalized to the $\mathrm{Pu}-\mathrm{Be}$ spectra that Anderson and Bond ${ }^{12}$ obtained by a different technique (Figure 8 ). The corrected data provided additional calibration points and indicated that the spectrometer responded properly to neutrons of different energies in the measurement range of 1.25 to $8.67 \mathrm{MeV}$. 


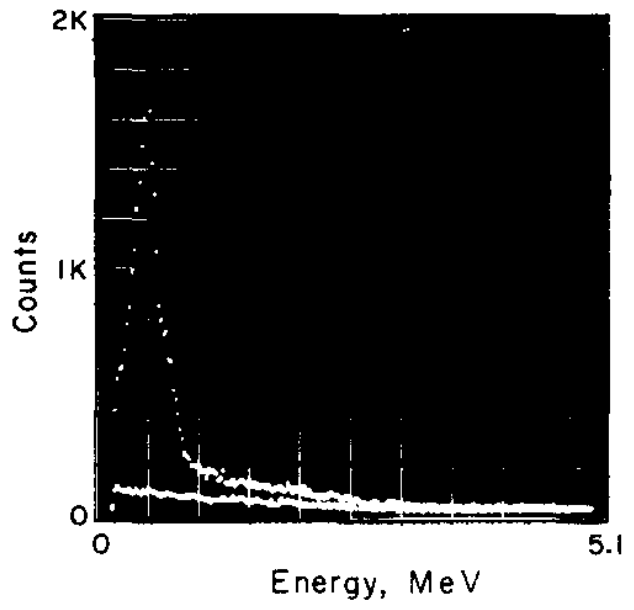

2K Full Scale to Show Complete

Spectra. Bottom Curve Is Background

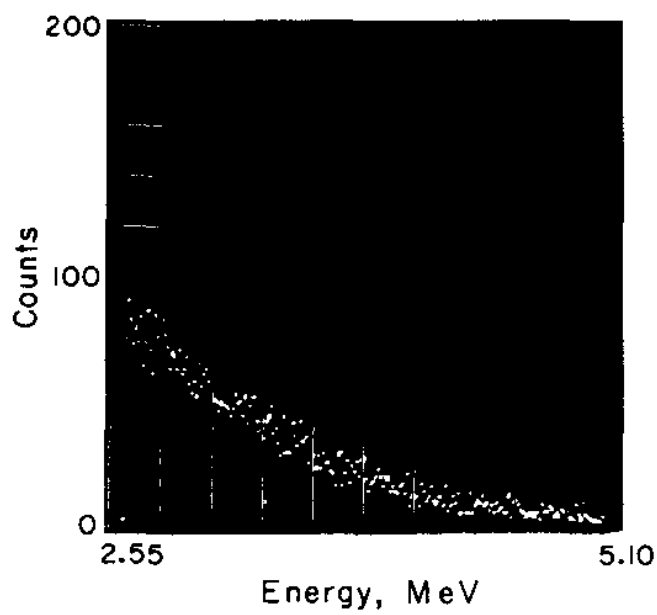

Upper 100 Channels of Signal at 200 Counts Full Scale to Enhance High Energy Region

FIG. $5{ }^{6}$ Li SPECTROMETER DATA FROM ALLOY 1 SOURCE 


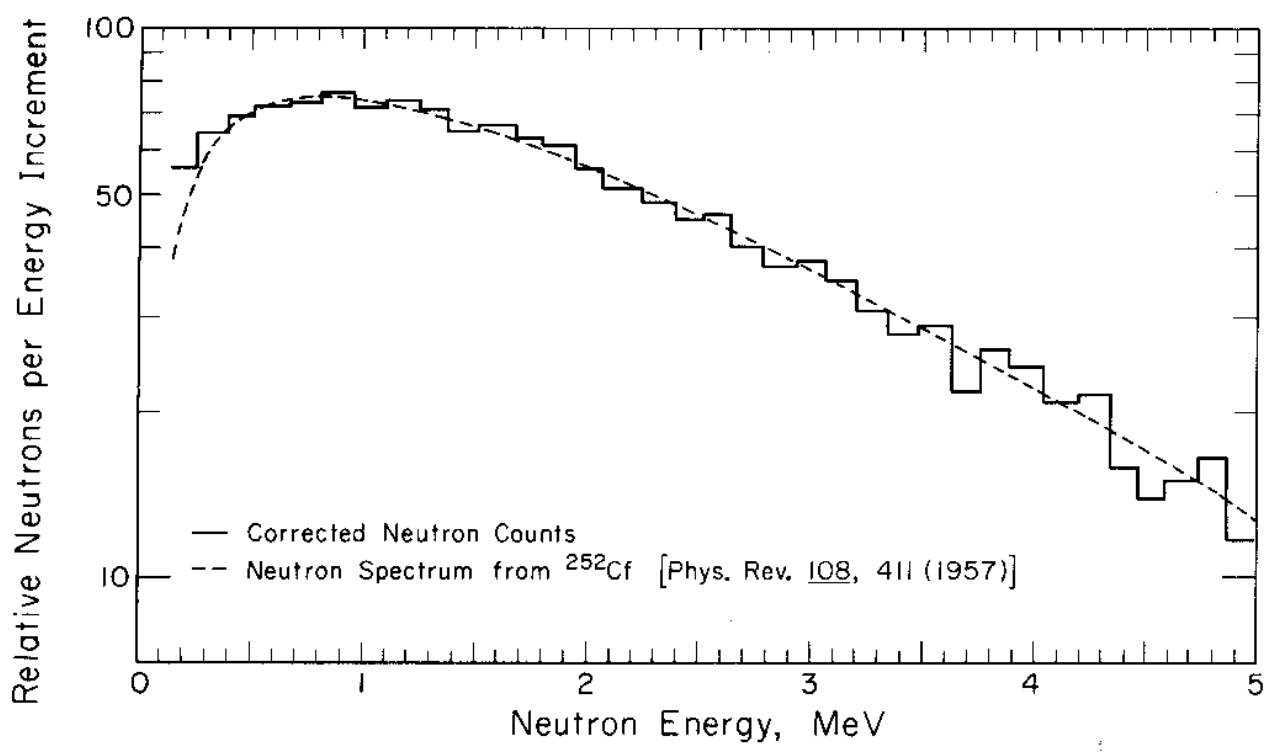

FIG. 6 NEUTRON SPECTRUM OF ALLOY 1 SOURCE WITH ${ }^{6} \mathrm{Li}$ SPECTROMETER

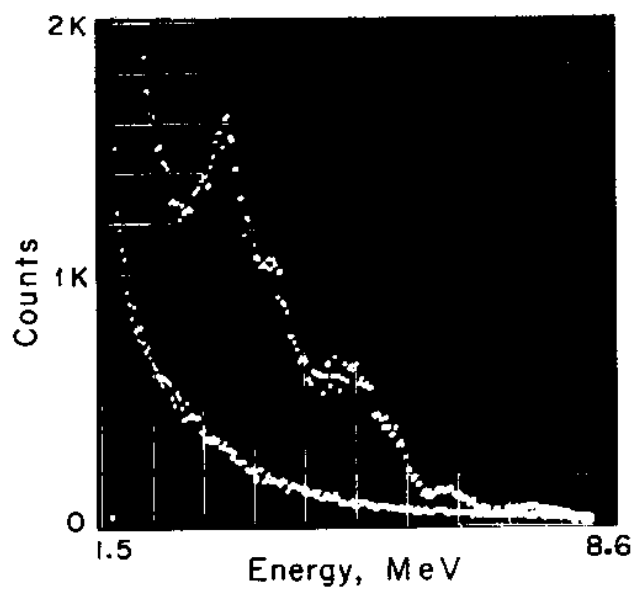

Bottom Curve Is ${ }^{3} \mathrm{He}$ Data

from Alloy 1 Source

FIG. $7{ }^{3} \mathrm{He}$ SPECTROMETER DATA FROM PU-Be SOURCE 


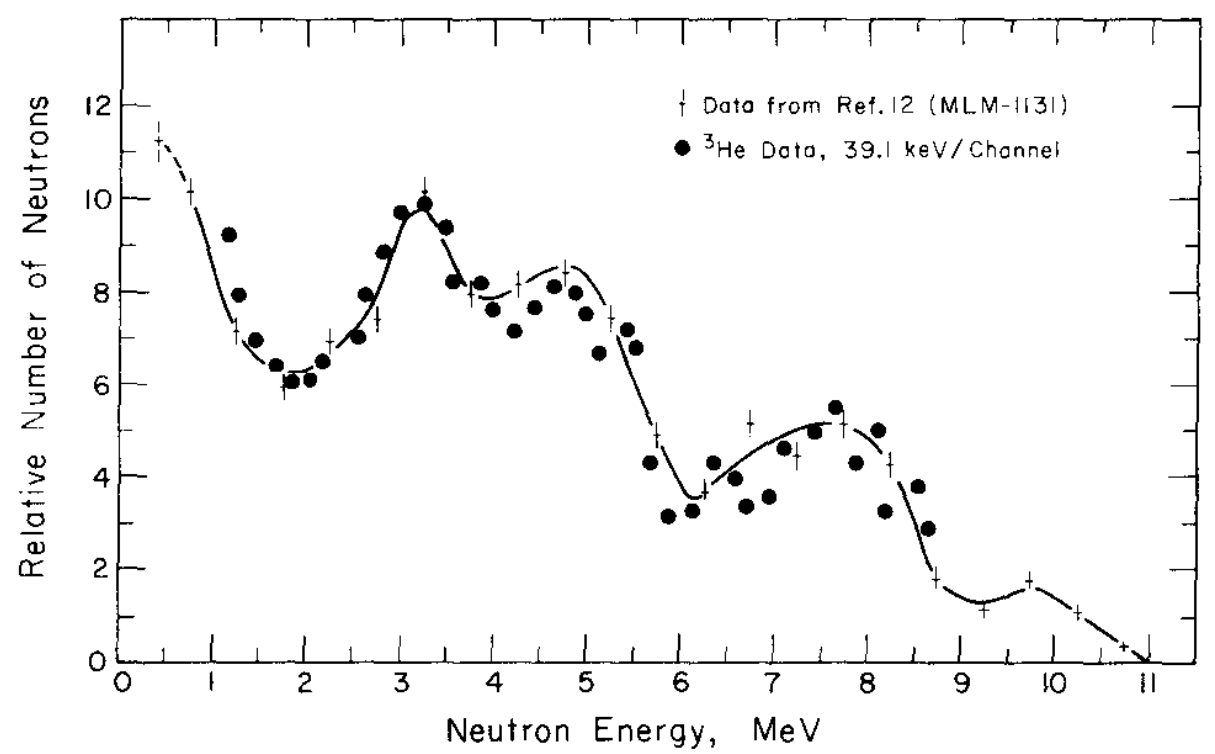

FIG. 8 NEUTRON SPECTRUM OF PU-Be SOURCE WITH ${ }^{3} \mathrm{He}$ SPECTROMETER

\section{CONCLUSION}

Neutron production from $(\alpha, \mathrm{n})$ reactions is insignificant in the ${ }^{252} \mathrm{Cf}$ wire sources currently produced at SRL. The neutron counting techniques and instrumentation would have detected a variation of about $1.5 \%$ from the spectrum of a pure ${ }^{252} \mathrm{Cf}$ source. 


\section{REFERENCES}

1. Califormium-252 Progress, Nos. 1-15 (1969-73). USAEC, Savannah River Operations Office, Aiken, S. C.

2. W. C. Mosley, P. K. Smith, and P. E. McBeath. "Palladium-

${ }^{252} \mathrm{Cf}$ Oxide Cermet, An Improved Form for ${ }^{252} \mathrm{Cf}$ Neutron Sources." Trans. Amer. Nucl. Soc. 15 (1), 288 (1972).

3. J. H. Roberts. Neutron Yields of Several Light Elements Bombarded with Polonium Alpha Particles. Report MDDC731 , Los A1amos National Laboratory, Los Alamos, N. M (1944).

4. I. A. Serdivkova, A. G. Krabakhpashev, and E. M. Tsenter. "Investigation of the $(\alpha, n)$ Reaction on Oxygen." Invest. Akad. Nauk USSR Ser. Fiz. 21, 1018 (1957).

5. T. R. Herold. "Neutron Spectrum of ${ }^{238} \mathrm{PuO}_{2}$." Nuclear Applications 4, 19 (1968)

6. W. R. McDonell, A. R. Boulogne, J. P. Faraci, S. F. Peterson, B. L. Dahlen, W. C. Mosley, D. J. Mahoney, and V. Whatley. "Preparation of Industrial Californium-252 Neutron Sources at Savannah River Laboratory." Neutron Sources and Applications. American Nuclear Society National Topical Meeting, Apri1 19-21, 1971, Augusta, Georgia. USAEC Report CONF-710402, Vol. II, 1-72 (1971).

7. T. R. Herold. "Neutron Spectrum of ${ }^{238} \mathrm{PuF}_{4}$." Nucl. Instr. Meth. 71, 40-44, (1969).

8. T. R. Herold. Energy Spectra of Neutrons and Garma Rays from Spontaneous Fission of ${ }^{244} \mathrm{Cm}$. USAEC Report DP-949, E. I. du Pont de Nemours and Co., Savannah River Laboratory, Aiken, S. C. (1965).

9. T. L. Yang. "Investigation of a ${ }^{6} \mathrm{Li}$ Semiconductor Sand wich Spectrometer Characteristics and Performance." Nucl. Inetr. Meth. 100, 533 (1972).

10. A. B. Smith, P. R. Fields, and J. H. Roberts. "Spontaneous Fission Neutron Spectrum of ${ }^{252} \mathrm{Cf} . "$ Phys. Rev. 108, 411 (1957).

11. M. G. Silk and S. B. Wright. Neutron Spectral Measurements over a Wide Energy Range Using a Single Semiconductor Spectrometer. United Kingdom Atomic Energy Authority Report AERE-6060, Harwel1, England (1971).

12. M. Edward Anderson and William H. Bond, Jr. The Neutron Spectrum of a Plutonium-BerylZium Source. USAEC Report MLM-1131, Monsanto Research Corporation, Miamisburg, Ohio (1964). 